\title{
Article \\ Organocatalytic Asymmetric Michael Addition in Aqueous Media by a Hydrogen-Bonding Catalyst and Application for Inhibitors of $\mathrm{GABA}_{B}$ Receptor
}

\author{
Jae Ho Shim ${ }^{1, *}$, Yeonsun Hong ${ }^{2}$, Ji Hae Kim ${ }^{1}$, Hyeon Soo Kim ${ }^{1, *}$ and Deok-Chan Ha ${ }^{3, *}$ \\ 1 Department of Anatomy, Korea University College of Medicine, 126-1, Anam-dong 5-ga, Seoul 02841, Korea; \\ jiihaek@korea.ac.kr \\ 2 David H. Smith Center for Vaccine Biology and Immunology, Department of Microbiology and Immunology, \\ University of Rochester, Rochester, NY 14642, USA; yeonsun_hong@urmc.rochester.edu \\ 3 Department of Chemistry, Korea University College of Science, Anam-ro, Seoul 136701, Korea \\ * Correspondence: shimjh3000@korea.ac.kr (J.H.S.); anatomykim@korea.ac.kr (H.S.K.); \\ dechha@korea.ac.kr (D.-C.H.); Tel.: +82-2-2286-1151 (H.S.K.)
}

check for

updates

Citation: Shim, J.H.; Hong, Y.; Kim, J.H.; Kim, H.S.; Ha, D.-C.

Organocatalytic Asymmetric Michael Addition in Aqueous Media by a Hydrogen-Bonding Catalyst and Application for Inhibitors of $\mathrm{GABA}_{B}$ Receptor. Catalysts 2021, 11, 1134 https://doi.org/10.3390/catal11091134

Academic Editors: Cristina Trujillo and Takeshi Ohkuma

Received: 27 July 2021

Accepted: 18 September 2021

Published: 21 September 2021

Publisher's Note: MDPI stays neutral with regard to jurisdictional claims in published maps and institutional affiliations.

Copyright: (c) 2021 by the authors. Licensee MDPI, Basel, Switzerland This article is an open access article distributed under the terms and conditions of the Creative Commons Attribution (CC BY) license (https:// creativecommons.org/licenses/by/ $4.0 /)$.

\begin{abstract}
Catalysts based on $(R, R)$-1,2-diphenylethylenediamine are, as chiral organic catalysts, applied to the asymmetric Michael addition to $\alpha, \beta$-unsaturated nitroalkenes under neutral conditions. The role of an aqueous medium for organic catalytic activity can be reversed concerning hydrophilic-hydrophobic function depending on the reaction conditions. In this study, to provide an environmentally friendly system, the thiourea-based catalyst substituted with $3,5-\left(\mathrm{CF}_{3}\right)_{2}-\mathrm{Ph}$ was used in water solvents. The hydrophobic effect of the substituent provided fast reaction, high chemical yield, and mirror-image selectivity. This reaction allowed the preparation of $\mathrm{GABA}_{\mathrm{B}}$ agonists in an optically pure manner. Additionally, GABA ( $\gamma$-aminobutyric acid) analogs such as baclofen and phenibut were synthesized as $R$-type $S$-type with high optical purity.
\end{abstract}

Keywords: Michael addition; inhibitor of $\mathrm{GABA}_{\mathrm{B}}$ receptor; organic chemistry; calcium release

\section{Introduction}

Organic catalysts composed of carbon, hydrogen, sulfur, and other nonmetal elements are commonly referred to as "organocatalysts." Stereoselective organocatalysts have been extensively studied, although metal-catalyzed asymmetric reactions tend to exhibit higher enantioselectivities than organocatalysts [1].

However, metal catalysts incur higher processing costs, and the metals are often retained in the products in ppm-level concentrations, thereby lowering the pharmaceutical purity of the products. Furthermore, metal catalysts are unstable in the presence of moisture. Thus, to overcome such disadvantages, research on stereoselective synthesis using organocatalysts has gained significant attention [2,3]. Since the conceptual establishment of organocatalysts, the application of organocatalytic reactions in asymmetric synthesis has been widely investigated, leading to significant advances in the area of organic synthesis [4-6]. In addition, following the establishment of the concept of "on water" organic synthesis by Sharpless et al. [7], Marcus's theory of catalysis via hydrogen bonding was proposed [8]. Over the past decade, numerous examples of organic reactions using water as a solvent have been reported, and water-based asymmetric catalytic reactions exhibiting high yields and good stereoselectivities have been investigated [9-13].

As a result, considerable progress has been made toward the synthesis of environmentally friendly organocatalysts. However, with the continuous emergence and establishment of new concepts, novel eco-friendly organocatalysts and reactions must be developed in order to improve product yields, reactivity, and selectivity. For example, in 2014, the Zhou group reported an "on water" reaction based on the fluorine effect [14]. In the non-catalyzed reactions of aldehydes, activated ketones, and isatylidene malononitriles in the presence of 
water, difluoroenoxysilane derivatives are commonly employed, where the fluorine atoms form hydrogen bonds with water [15-19]. This hydrogen bonding stabilizes the negative charge of the reactants and the transition state, thereby promoting the reaction in the presence of water. We have also previously reported a catalytic reaction that is stable in water with a short reaction time, high yield, and high stereoselectivity. This Michael reaction, which is important for the formation of $\mathrm{C}-\mathrm{C}$ bonds, was applied in a green example of an asymmetric Michael addition reaction in the presence of a chiral bifunctional organic catalyst (Figure 1) [20-24].

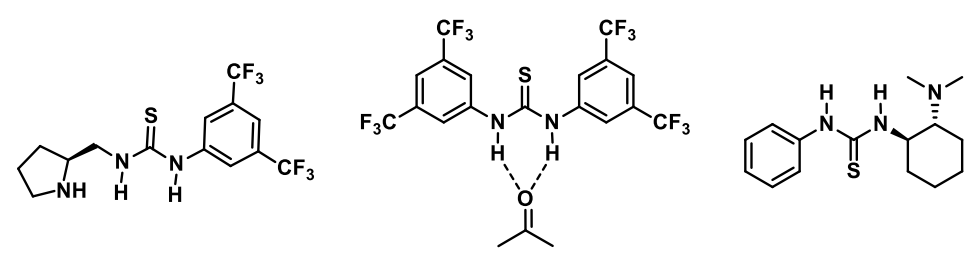

b.

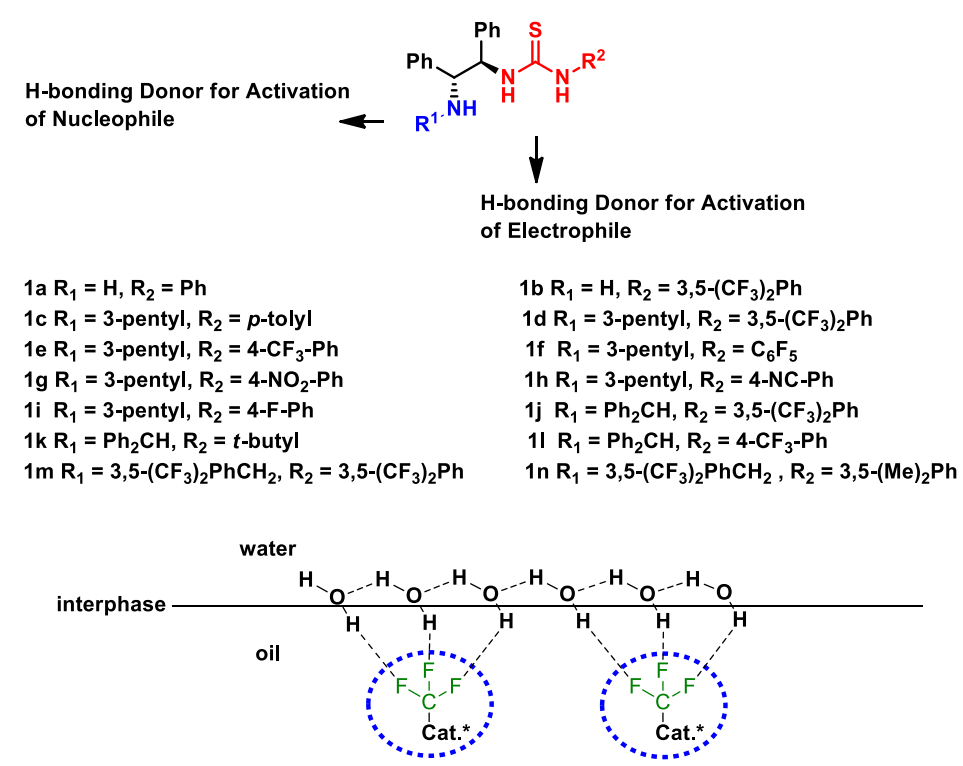

Figure 1. Non-covalent organic catalysts in aqueous media. (a). Chiral, achiral hydrogen-bonding catalysts are widely used for asymmetric reactions. (b). Thiourea catalyzes several reactions by forming hydrogen bonds with the substrate. (c). Chiral hydrogen-bonding catalysts used for asymmetric C-C Michael reactions.

Using a nitroalkenes group as a Michael acceptor makes it easy to apply to the Michael reaction as an electrophile due to the strong electron deficiency of the nitro group, and the compound produced after reaction with a chalcone group can be converted into keto, amino, cyano, and carboxylic acid groups [25]. In this study, we report using $(R, R)-1,2-$ diphenylethylene diamine as the basic framework for chiral catalysts and the thiourea moiety is functionally active. The Zhou group also reported that the $3,5-\left(\mathrm{CF}_{3}\right)_{2}$ groups present in the catalyst can form C-F...H-O bonds with water molecules at the interface with the organic phase.

In this way, hydrogen bonding in the hydrophobic portion $\left(3,5-\left(\mathrm{CF}_{3}\right)_{2}-\mathrm{Ph}\right.$ groups $)$ of the thiourea catalyst can stabilize the catalyst, thereby lowering the energy level of the lowest unoccupied molecular orbital (LUMO) of the electrophile itself and the highest occupied molecular orbital (HOMO) of the nucleophile, thus stabilizing the transition state [26-30]. Such a proximity enables better orbital overlapping and therefore increases bond-forming events. Therefore, our reaction was carried out by referring to previously 
published papers and determining whether any catalyst was needed to proceed in this reaction $[31,32]$.

\section{Results and Discussion}

The reaction was investigated by applying it to the Michael reaction of nitroalkene, malononitrile, and nitro ester through a chiral hydrogen-bonding catalyst used for asymmetric C-C Michael reaction. Initially, thiourea catalysts bearing no alkyl group on one amine moiety were employed (Figure 1a,b), and the reaction at room temperature (rt) using toluene as the solvent produced no additional reaction product (Supplementary Table S1). The reaction was then attempted using a thiourea-based catalyst, in which the 3-pentyl group was substituted on the amine (Figure 1,1c-1i). Among the various thiourea catalysts bearing 3-pentyl groups, the catalyst bearing an electron-withdrawing fluoro group (Figure 1,1i) gave a higher yield and similar stereoselectivity compared with that bearing an electron-donating para-tolyl group (Figure 1,1c). The highest yield and stereoselectivity were obtained using the catalyst substituted with the 3,5-bis-(trifluoromethyl group) (Figure 1,1d). Additional experiments were then carried out to confirm this result; it was found that good selectivity and yield were obtained even when other alkyl groups were substituted on the amine, although the incorporation of the 4-tolyl-Ph, 4-fluoro-Ph group (Figure 1,1c,1i) gave lower yields and enantiostereoselectivities. Therefore, the obtained results suggested that catalyst $1 \mathrm{~d}$ was optimal for this reaction at $\mathrm{rt}$ (Supplementary Table S1). To investigate the effect of the catalyst on the asymmetric Michael reaction between malonate and nitroalkene, the reaction was carried out using trans- $\beta$-nitrostyrene. A range of malonates was examined in the presence of various catalysts, in which the $(R, R)-1,2$ diphenylethylenediamine unit was substituted with a range of $R^{1}$ and $R^{2}$ groups at the amine site [33]. We found that the yield and stereoselectivity afforded by the catalyst substituted with a tert-butyl group (Figure 1,1k) were higher than those afforded by the catalyst substituted with the $3,5-\left(\mathrm{CF}_{3}\right)_{2} \mathrm{Ph}$ group (Figure $\left.1,1 \mathrm{j}\right)$ when the reaction was carried out in toluene. In contrast, when water was used as the solvent, the yield and stereoselectivity were significantly improved when $1 j$ was employed (Supplementary Table S2). These results therefore indicate that hydrogen bonding between the fluorine group of $3,5-\left(\mathrm{CF}_{3}\right)_{2} \mathrm{Ph}$ and the water solvent molecules enhances the reaction rate, yield, and stereoselectivity and that superior results are obtained when the reaction is carried out in water. We also found that in toluene, the yield tended to decrease as the malonate $\mathrm{R}$ group became bulkier, while the yield increased in water. Furthermore, in the presence of catalyst $1 \mathrm{j}$, the addition of benzoic acid prevented self-condensation between the malonate units, resulting in comparable yields but reduced reaction times (i.e., approximately $3 \mathrm{~h}$ ) (Supplementary Table S3). To further investigate the hydrophobic effect of the fluorine group, a 3,5- $\left(\mathrm{CF}_{3}\right)_{2} \mathrm{PhCH}_{2}$ group was added to the catalyst. [34] Thus, when the catalyst containing the 3,5-(Me $)_{2} \mathrm{Ph}$ group was used as a control, $1 \mathrm{n}$ (containing the $3,5-\left(\mathrm{CF}_{3}\right)_{2} \mathrm{PhCH}_{2}$ and $3,5-(\mathrm{Me})_{2} \mathrm{Ph}$ groups) was obtained in improved higher yield and exhibited stereoselectivity under neat conditions. However, when water was used as the solvent, $1 \mathrm{~m}$ (containing the $3,5-(\mathrm{Me})_{2} \mathrm{Ph}$ and 3,5-( $\left(\mathrm{CF}_{3}\right)_{2} \mathrm{PhCH}_{2}$ groups) was obtained in a shorter reaction time than $1 \mathrm{n}$ (Supplementary Table S4).

With the optimized reaction conditions in hand, the scope of the malonate substrate was examined using $1 \mathrm{~m}$ as a catalyst (Table 1 ). To demonstrate the effect of hydrogen bonding between fluorine and hydrogen, the asymmetric Michael addition reaction was carried out in water, which is able to form hydrogen bonds. Overall, good reaction yields and stereoselectivities were obtained, although the reaction rate tended to be lower in the presence of larger malonate $\mathrm{R}$ groups due to steric hindrance.

As outlined in Figure 2, the scope of the nitrostyrene substrate was examined next [35-38]. Poorer results were obtained compared with those using the non-substituted $\beta$-nitrostyrene, although 4-Br and 4-Cl substituted $\beta$-nitrostyrenes gave good yields and stereoselectivities. In contrast, substitution with 4-OMe and 2-OMe groups gave lower yields and stereoselectivities. These results indicate that for $\beta$-nitrostyrenes bearing electron-withdrawing 
groups, the double bond of the $\beta$-nitrostyrene is more electron-deficient, which facilitates the reaction. This should allow the preparation of bioactive compounds such as baclofen via the reaction between diethyl malonate and the $4-\mathrm{Cl}$ substituted $\beta$-nitrostyrene.

Table 1. Malonate scope of the Michael reaction using catalyst $1 \mathrm{~m}$.

\begin{tabular}{|c|c|c|c|c|c|}
\hline & 1 equiv. & 2 equiv. & & & \\
\hline Entry & $\mathbf{R}$ & Ar & Time (min) & Yield (\%) ${ }^{b}$ & ee $(\%)^{c}$ \\
\hline 1 & $\mathrm{Me}$ & $\mathrm{Ph}$ & 30 & 99 & 99 \\
\hline 2 & Et & $\mathrm{Ph}$ & 40 & 99 & 99 \\
\hline $3^{d}$ & $\mathrm{Et}$ & $\mathrm{Ph}$ & 10 & 99 & 99 \\
\hline $4^{\mathrm{e}}$ & Et & $\mathrm{Ph}$ & 10 & 99 & 99 \\
\hline
\end{tabular}

a Using $0.4 \mathrm{~mL}$ solvent on a $0.1 \mathrm{mmol}$ scale. ${ }^{\mathrm{b}}$ Isolated yield. ${ }^{\mathrm{c}}$ Determined by chiral HPLC. ${ }^{\mathrm{d}}$ The reaction was run using $5 \mathrm{~mol} \%$ catalyst. ${ }^{\text {e }}$ The reaction was run using $5 \mathrm{~mol} \%$ benzoic acid.

Next, we investigated the trans-chalcone species of this asymmetric Michael addition, as summarized in Figure 3. The substituents' position and electronic properties on the aromatic ring have a negligible effect on the reactive enantioselectivity. In fact, various transchalcones, including furan or phenyl substituents, react with nitro-ethyl-esters to provide the corresponding adducts with high enantioselectivity and good yields. Additionally, after de-esterification using sodium hydroxide, the final product obtained was $S$ enantiomer. Therefore, to elucidate the catalytic mechanism underlying the Michael reaction of this trans-chalcone, we calculated the quantum energy of the optimized structure of TS (transition states) and IM (intermediate) step-by-step through DFT quantum calculation. First, as shown in Figure 4, the optimization structure scheme confirmed each step through quantum calculation.

The transition state of this reaction is similar to that of the catalyst [38], where the hydrogen atom in the amine of the catalyst thiourea moiety forms a hydrogen bond with the oxygen atom of the unsaturated nitroalkene and nitro-ethyl ester. Additionally, the unsaturated nitroalkyne and nitro-ethyl ester are fixed in their conformation, thereby limiting the reaction of the double bond to a single side. Moreover, the reaction course is determined by the attack on the electrophically activated $\beta$-position of nitroethene $[39,40]$. Therefore, we predicted the TS of the re or si face of the unsaturated nitroalkyne as in the TS in Figure 4. In addition, as shown in Figure 4a of TS2, the cyano group of malononitrile forms a hydrogen bond with the alkylated amine of the catalyst. Next, the malononitrile approaches the re-face, the backside of the unsaturated compound, and finally, the intermediate IM3 with a selective $R$ configuration is formed. In the case of the nitro ethyl ester in Figure $4 \mathrm{~b}$, the difference in the thermal energy between TS1 and TS2 was $1.148 \mathrm{kcal} / \mathrm{mol}$ more stable for TS2 through DFT calculation. Following TS2 formation, it was expected to go through the same shape as IM2, and the final formation result was expected to be an $S$-form product. Furthermore, as shown in Figure 4, it was predicted that the fluorine atoms of the trifluoromethyl group interacted with the phenyl group of the catalyst and with the protons of the water solvent via hydrogen bonds. Therefore, as a result of confirming this part's solvent effect through ${ }^{19} \mathrm{~F}$ NMR (SI. 60 page), it was affected by the shift of the fluorine peak of the catalyst under the $\mathrm{MeOH}-d_{4} / \mathrm{D}_{2} \mathrm{O}(1: 1)$ condition. As a result, below, we confirmed the solvent effect and reaction mechanism through DFT calculation for the above reasons. 
a.
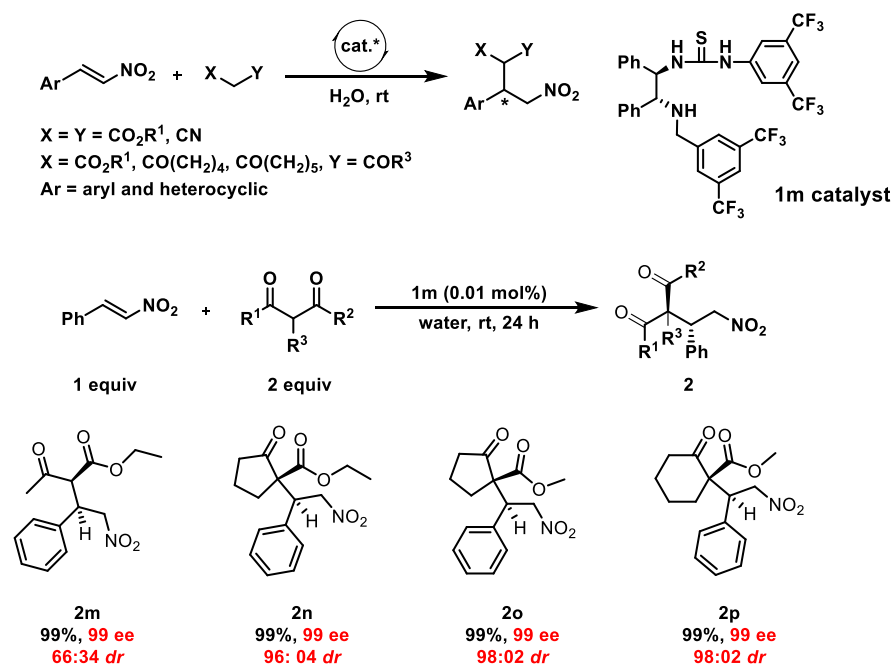

c.

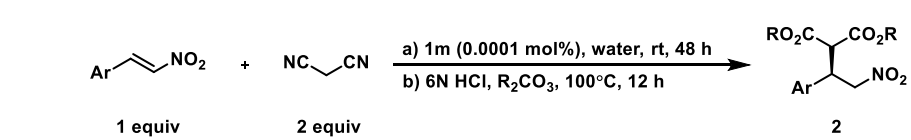

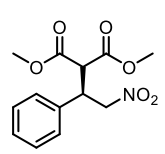

$\stackrel{2 a}{98 \%, 99 \text { ee }}$

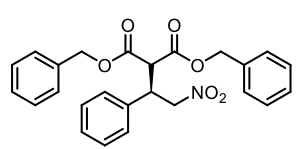

$2 e$
$94 \%, 99$ ee

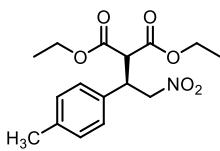

$\underset{98 \%, 93 \text { ee }}{2 i}$

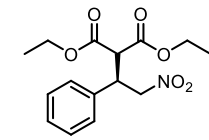

$2 b$
$98 \%, 99$ ee

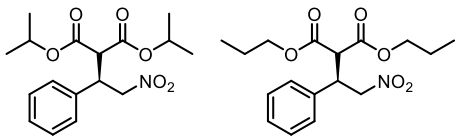

$2 c$
$97 \%, 99$ ee

$2 \mathrm{~d}$
$94 \%, 99$ ee

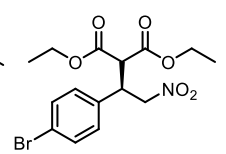

$2 \mathrm{~g}$
$98 \%, 99$ ee

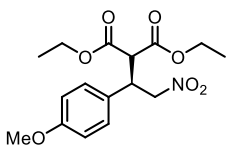

$2 k$
$94 \%, 91$ e

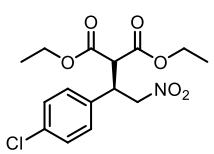

$\stackrel{2 h}{98 \%, 99 \text { ee }}$

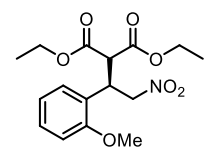

21
$92 \%, 96$ ee

Figure 2. $R$-form products of the Michael reaction using $\beta$-nitrostyrenes. (a) Synthesis concept and reaction scope of the substrate for Michael reaction. (b) Scope of the Michael reaction using a range of $\beta$-keto esters. The reaction was conducted by using nitrostyrene ( $14 \mathrm{mmol})$, $\beta$-keto ester $(28 \mathrm{mmol})$, water $(20 \mathrm{~mL})$, and catalyst $1 \mathrm{~m}$ at room temperature. (c) Scope of the Michael reaction using a range of malononitriles. The reaction was conducted by using nitrostyrene ( $27 \mathrm{mmol})$, malononitriles $(54 \mathrm{mmol})$, water $(50 \mathrm{~mL})$, and catalyst $1 \mathrm{~m}$ at room temperature.

The relative free energies and thermal energies for the Michael reaction step are shown in Figure 5 through DFT calculation. The Michael addition of nitro ethyl ester and malononitrile to nitro compounds using a thiourea-DPEN-based organocatalyst was accelerated due to the hydrophobicity of the fluorine substituted organocatalyst [40-43]. Therefore, to predict the solvent effect of the catalyst, we compared the relative free energy and thermal energy of TS in water, toluene, and gas state, respectively, as shown in Supplementary Figure S1, where the energy in the state in which water was a solvent was the lowest and was stable. Additionally, as a result of confirming the solvent effect (toluene, water, and gas) for the addition reaction of diethyl malonate, the relative free energy was low when water was used as a solvent (Supplementary Figure S2). Thus, when the solvent of Michael's reaction is water, as the polarity of the catalyst increases, 
the reactivity increases, possibly due to the effect of the hydrophobic group of the catalyst. In addition, a comparison of the relative free energies during the interfacial reaction between the hydrophobic substituent of the catalyst $1 \mathrm{~m}$ and $\mathrm{H}_{2} \mathrm{O}$ was compared in an aqueous two-component mixture $\left(\mathrm{H}_{2} \mathrm{O}+\right.$ Solvent). As a result of the comparison, it was confirmed that it had the lowest relative free energy when water was used as a solvent. These results suggest that the relative energy can be stabilized due to the hydrophobic effect of the hydration reaction, and thus the reactivity can be increased.

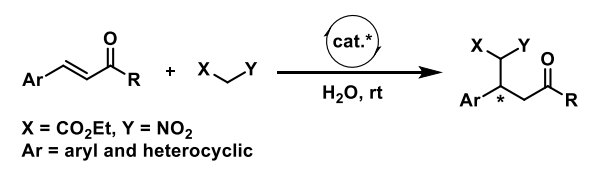

b.
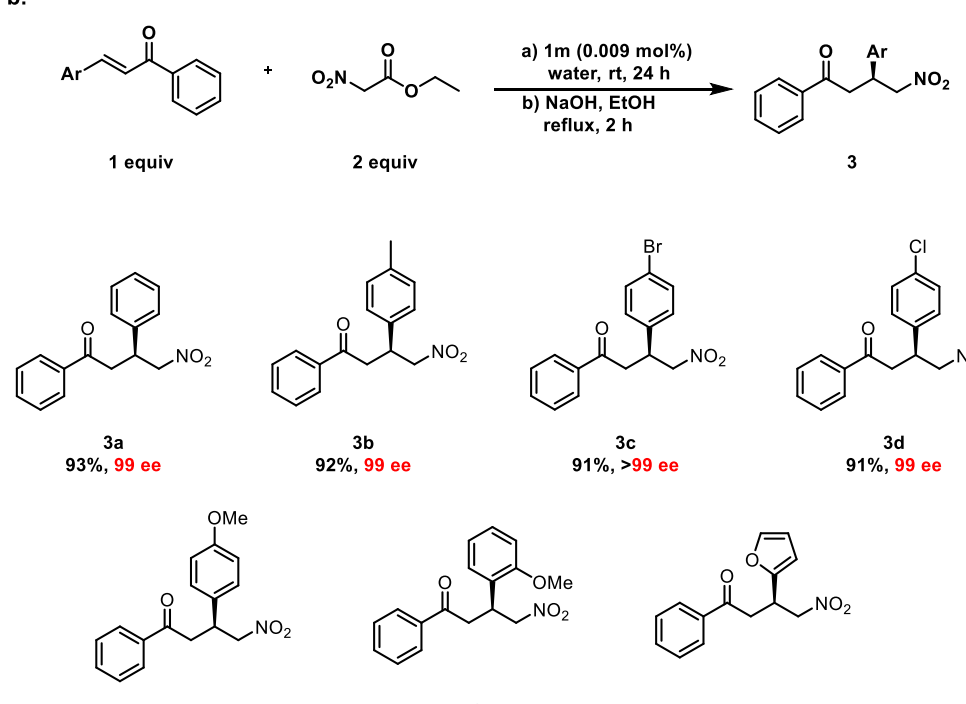

$3 b$
$92 \%, 99$ ee
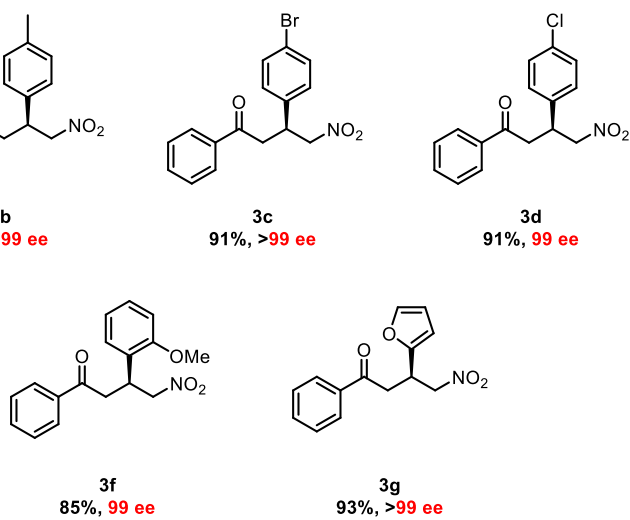

Figure 3. S-form products of the Michael reaction using catalyst $1 \mathrm{~m}$. (a) Synthesis and reaction scope of the substrate for Michael reaction. (b) Trans-chalcone scope of the Michael reaction. The reaction was conducted using trans-chalcone ( $15 \mathrm{mmol})$, nitro-ethyl ester $(30 \mathrm{mmol})$, water $(30 \mathrm{~mL})$, and catalyst $1 \mathrm{~m}$ at room temperature.

As outlined in Figure $6 \mathrm{a}$, when $\mathrm{NiCl}_{2} \cdot 6 \mathrm{H}_{2} \mathrm{O}$ and $\mathrm{NaBH}_{4}$ were added to the $4-\mathrm{Cl}$ and $4-\mathrm{H}$ substituted $\beta$-nitrostyrenes, the nitro group was reduced and cyclized to obtain the corresponding pyrrolidinone (products 5e, 5f) [44,45]. Subsequent ring-opening of the pyrrolidinone ring gave a $\beta$-phenyl- $\gamma$-amino-buta-noic-acid (GABA) derivative (products $5 a, 5 b, 5 c, 5 d$ ). These substances, which can easily be converted into phenylpiracetam [46], have pharmacological effects as $\mathrm{GABA}_{B}$ agonists, muscle relaxants, and antidepressants $[47,48]$. Phenibut (3-phenyl-4-aminobutyric acid) is a GABA ( $\gamma$-aminobutyric acid)-mimetic psychotropic drug clinically used in its racemic form. The pharmacological activity of racemic phenibut relies on $R$-phenibut, which correlates with the binding affinity of enantiomers of phenibut to the $G_{A B A}$ receptor [49]. Moreover, the $G_{A B A}$ receptor binds to the $G$ protein to form a heterodimer of the $G_{A B A}$ and $G A B A_{B 2}$ subunits, both of which are required for functional activation of the $G_{A B A}$ receptor [50].

$\mathrm{GABA}_{B}$ receptors regulate neurotransmitter release by inhibiting $\mathrm{Ca}^{2+}$ influx through voltage-activated $\mathrm{Ca}^{2+}$ channels involved in slow synaptic inhibition [51]. Moreover, $\mathrm{GABA}_{B}$ receptor activation can be induced either by agonists such as GABA or baclofen or by positive allosteric modulators (PAMs) [52]. In particular, baclofen was approved for the treatment of seizures in the 1970s [53]. It has also recently emerged as a promising treatment for alcoholism [54]. In subsequent indications, very high doses of baclofen up to $400 \mathrm{mg}$ per day are prescribed to reduce and control alcohol intake [55]. These high- 
dose regimens are most likely to induce baclofen-induced mania symptoms (BIMS) [56]. This suggests that the putative antidepressant effect of baclofen may also be related to the isomer ( $R$-form, $S$-form) form of baclofen.

a.

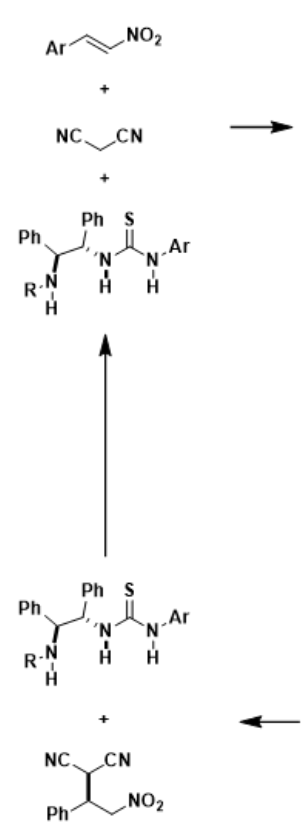

(R)-product

b.<smiles>CC=CC(=O)c1ccccc1</smiles><smiles>CCCOC(=O)C[N+](=O)[O-]</smiles>

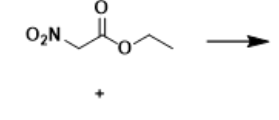

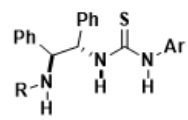

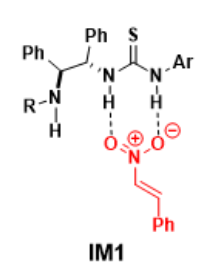

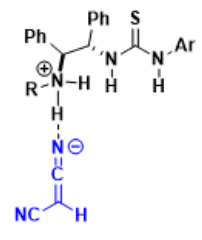

IM2
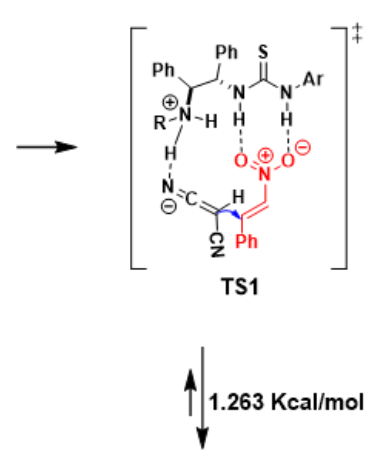

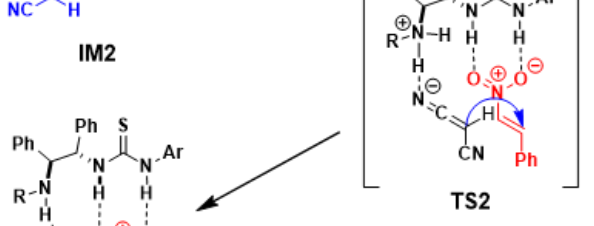

$\mathrm{NC}_{\mathrm{Ph}}$

IM3

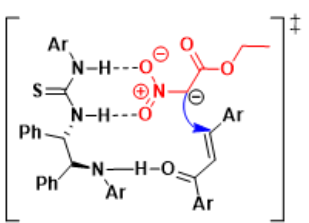

TS1

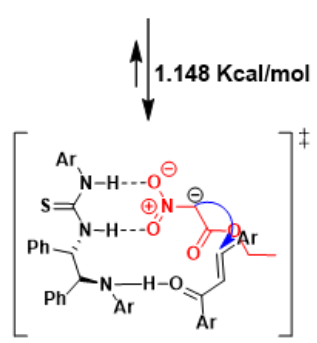

TS2<smiles>CCOC(=O)[C@H](CC(=O)c1ccccc1)[C@@H](C(=O)O)c1ccccc1</smiles><smiles>CCOC(=O)[C@H](O)[C@H](CC(=O)c1ccccc1)c1ccccc1</smiles>

(S)-product

Figure 4. Reaction mechanism inferred through expected transition states. $(R, R)$-1,2-diphenylethylenediamine (DPEN)-thiourea-catalyzed enantioselective Michael reaction calculated at the B3LYP/6-31G(d,p) level. (a) Expected $R$-form products mechanism of the substrate for Michael reaction. (b) Mechanism of expected $S$-form products of the Michael reaction.

Prior to confirming the $\mathrm{GABA}_{\mathrm{B}}$ receptor activation via these compounds, we assessed their cytotoxicity using HEK293T cells. As shown in Figure 7a, below $1 \mu \mathrm{M}$, none of the compounds have an effect on cell viability at a concentration. To determine differences in the biological functions induced by these compounds, we examined intracellular $\mathrm{Ca}^{2+}$ release in HEK293T cells in response to treatment with $R$-baclofen and $R$-phenibut and using RS-baclofen and phenibut as controls (Figure $7 \mathrm{~b}, \mathrm{c}$ ). The changes of intracellular $\left[\mathrm{Ca}^{2+}\right]$ concentrations were measured using Fluo-3-AM, a Ca ${ }^{2+}$ fluorescent indicator. We demonstrated that $R$-baclofen induced a higher intracellular $\mathrm{Ca}^{2+}$ release than $R S$ - 
baclofen. Taken together, our data show that as a drug, baclofen RS-type may induce differential calcium release activity depending on $R$ and $S$-types. This will in turn induce differential $G_{A B A}$ receptor activation. We conclude that the pharmacological activity of $R S$-phenibut depends on $R$-phenibut, which is related to the binding affinity of the enantiomer of phenibut to the $\mathrm{GABA}_{\mathrm{B}}$ receptor.

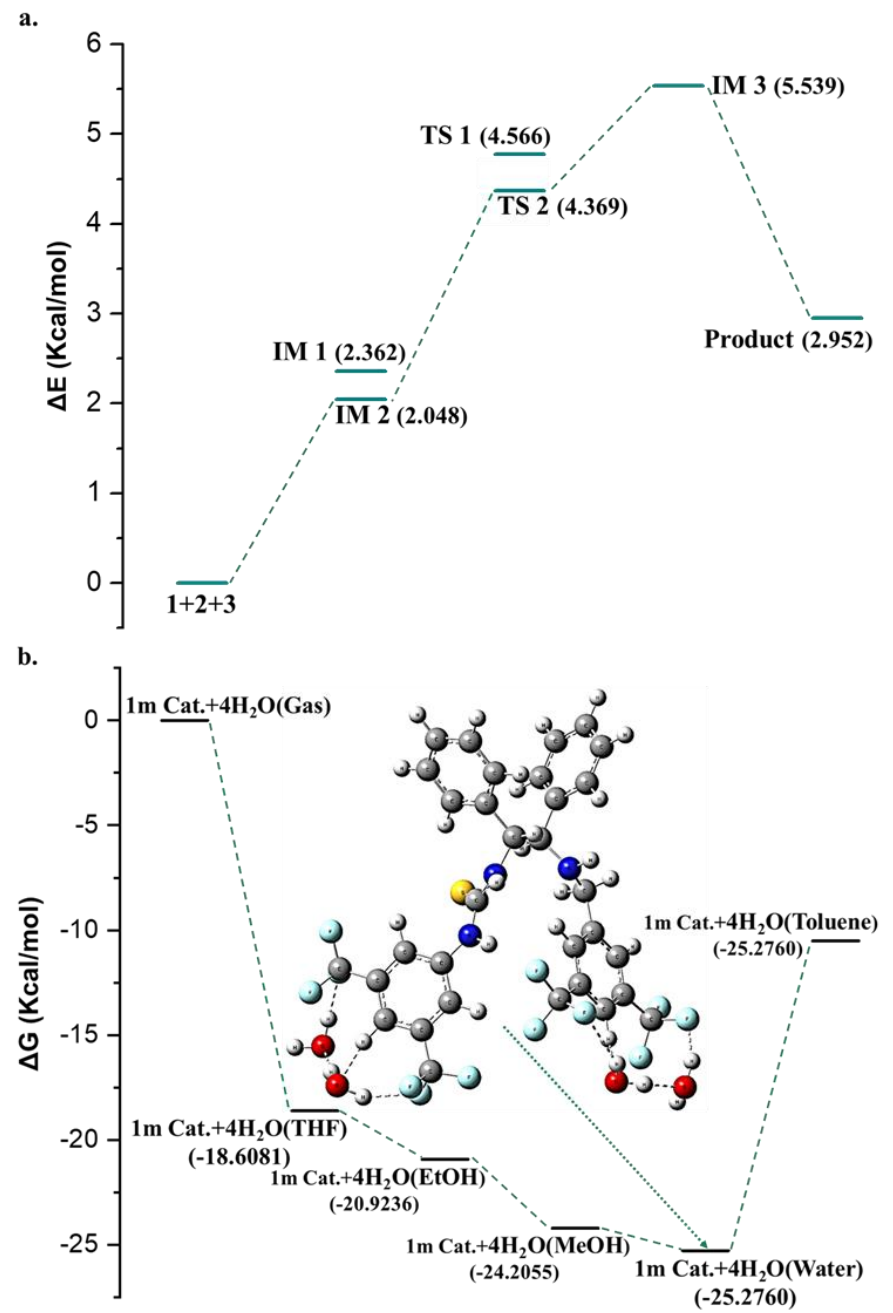

Figure 5. DFT-calculated energy diagram for the Michael reaction using $\beta$-nitrostyrenes. (a) $(R, R)-1,2-$ diphenylethylenediamine (DPEN)-thiourea-catalyzed enantioselective Michael reaction calculated at the B3LYP/6-31G(d,p) level. Expected thermal energy of the Michael reaction. (b) Representation of a $1 \mathrm{~m}$ catalyst at an aqueous binary mixtures calculated at the B3LYP/6-31G(d,p) level. 

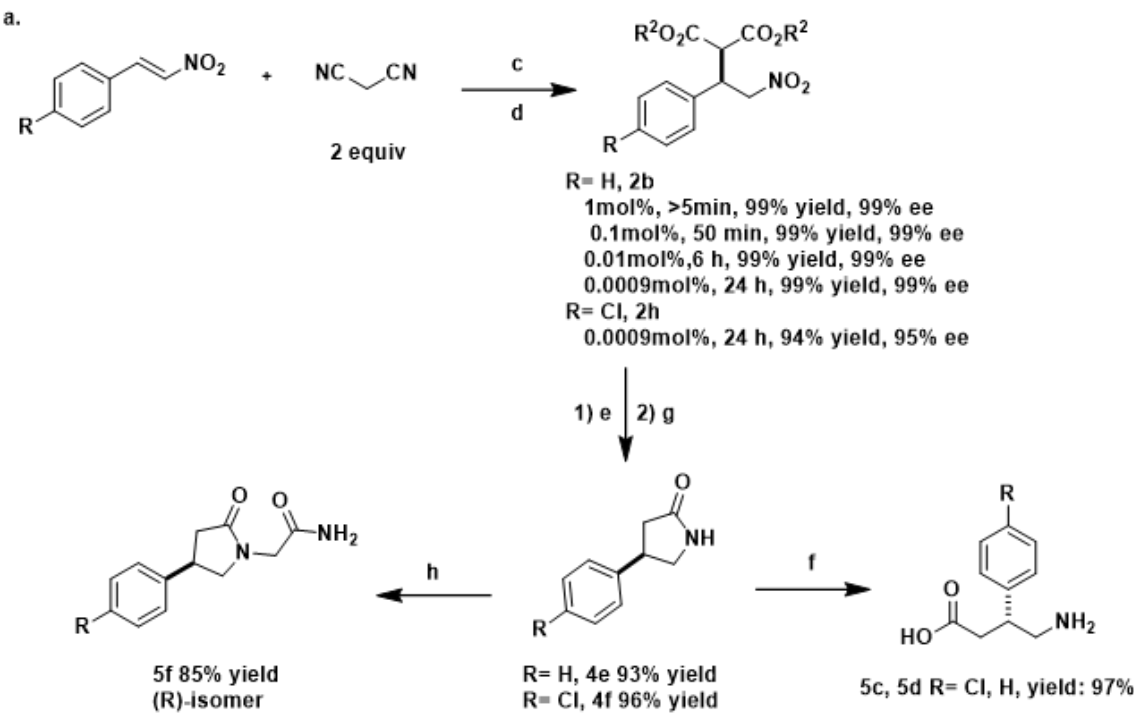

b.<smiles>[R]c1ccc(/C=C/C(=O)c2ccccc2)cc1</smiles><smiles>CCOC(=O)C[N+](=O)[O-]</smiles><smiles>[R]c1ccc(C(CC(=O)c2ccccc2)C[N+](=O)[O-])cc1</smiles>

$\mathrm{R}=\mathrm{H} .3 \mathrm{a} 93 \%$ yield, $99 \%$ ee $\mathrm{R}=\mathrm{Cl}, 3 \mathrm{~d} 96 \%$ yield, $99 \%$ ee
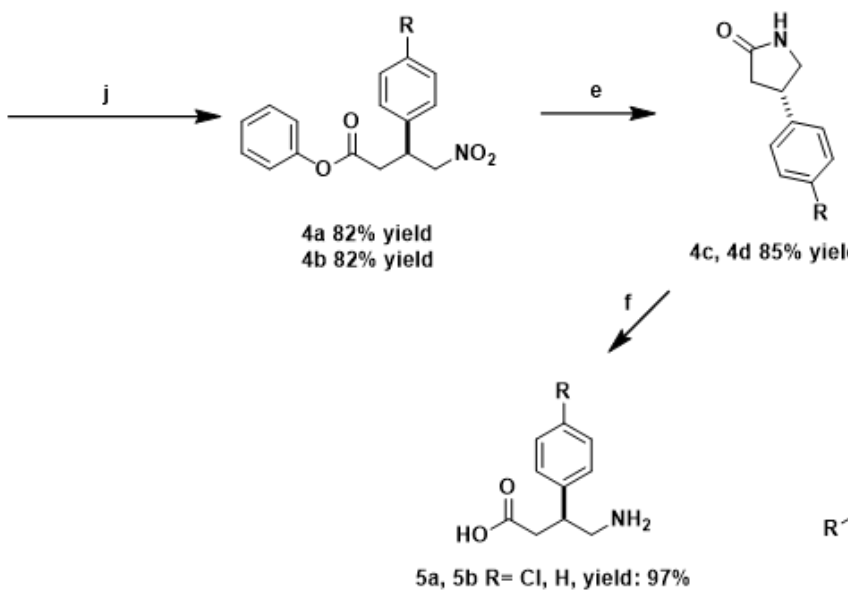

$4 c, 4 d 85 \%$ yield

$5 a, 5 b \mathrm{R}=\mathrm{Cl}, \mathrm{H}$, yield: $97 \%$

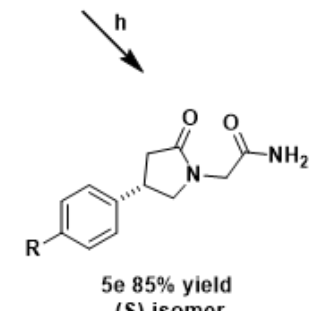

(S)-isomer

Figure 6. Possibility of application of product. Synthesis of pyrrolidinone derivatives (phenylpiracetam) and $\mathrm{GABA}_{\mathrm{B}}$ receptor (phenibut, baclofen). (a) The reaction was conducted using nitrostyrene (27 mmol), malononitriles (54 mmol), water $(50 \mathrm{~mL})$, and catalyst $1 \mathrm{~m}$ at room temperature. $(\mathbf{b})$ The reaction was conducted using trans-chalcone (15 mmol), nitro-ethyl ester (30 mmol), water (30 $\mathrm{mL})$, and catalyst $1 \mathrm{~m}$ at room temperature. (c) Catalyst $1 \mathrm{~m}(\mathrm{X} \mathrm{mol} \%)$, water, $\mathrm{rt}$, (d) $6 \mathrm{~N} \mathrm{HCl}, \mathrm{R}_{2} \mathrm{CO}_{3}, 100{ }^{\circ} \mathrm{C}$, $12 \mathrm{~h}$, (e) $\mathrm{NiCl}_{2} \cdot 6 \mathrm{H}_{2} \mathrm{O} / \mathrm{NaBH}_{4}, \mathrm{MeOH}, \mathrm{rt}, 6 \mathrm{~h}$, (f) $6 \mathrm{~N} \mathrm{HCl}, \mathrm{R}_{2} \mathrm{CO}_{3}, 100^{\circ} \mathrm{C}, 12 \mathrm{~h}$, (g) (1) $\mathrm{NaOH}, \mathrm{EtOH}$, rt, $0.5 \mathrm{~h}$, (2) Toluene, reflux, $0.5 \mathrm{~h}$, (h) (1) $\mathrm{NaH}, \mathrm{THF}, \mathrm{rt}, 6 \mathrm{~h}$, (2) $\mathrm{NH}_{3}, \mathrm{rt}, \mathrm{MeOH}, 5 \mathrm{~h}$, (i) $\mathrm{NaOH}, \mathrm{EtOH}$, reflux, $2 \mathrm{~h}$, (j) $m$-CPBA, TFA, $\mathrm{ClCH}_{2} \mathrm{CH}_{2} \mathrm{Cl}, 70{ }^{\circ} \mathrm{C}, 72 \mathrm{~h}$. 


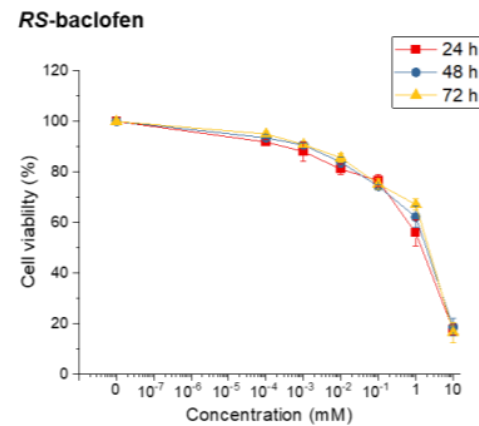

$R$-baclofen
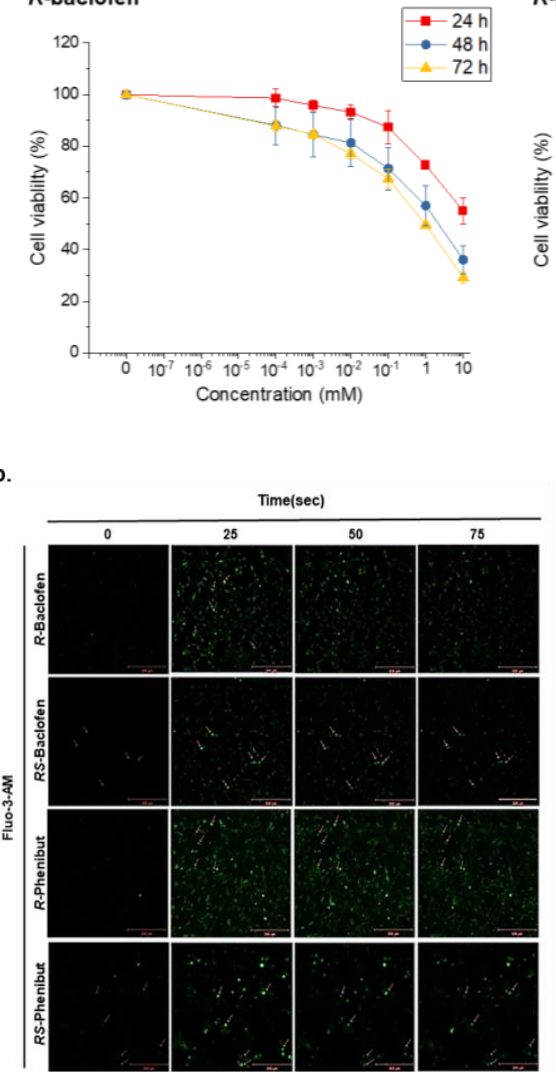

RS-phenibut

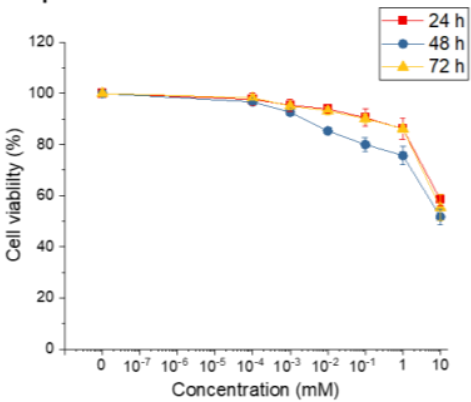

R-phenibut
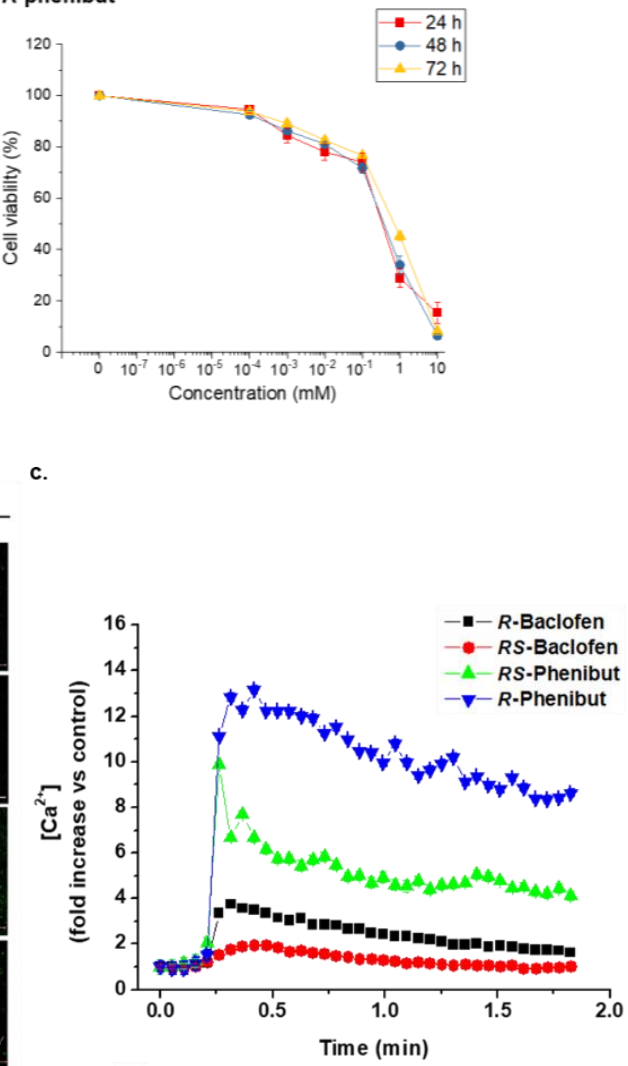

Figure 7. In vitro cell viability test and comparison of $\mathrm{Ca}^{2+}$ release in response to $R S$-baclofen, $R S$ phenibut, and $R$-phenibut with $R$-baclofen. (a) Cell viability analysis of the compounds against HEK293T cells. The cells were treated with $R$-baclofen, $R S$-baclofen, $R S$-phenibut, and $R$-phenibut for 24,48 , and $72 \mathrm{~h}$. The cell viability (\%) was calculated as per the CCK-8 assay protocol. Each value represents the mean \pm SEM of three independent experiments. (b) Representative Fluo-3-AM fluorescence images of the intracellular $\mathrm{Ca}^{2+}$ level in HEK293T cells treated with $R S$-baclofen, $R$ baclofen, $R S$-phenibut, and $R$-phenibut $(1 \mu \mathrm{M}$, final concentration). $R$-baclofen was used as a positive control. Scale bar: $200 \mu \mathrm{m}$. (c) The intensity of $\mathrm{Ca}^{2+}$ release over time after treatment with $R S$-baclofen, $R$-baclofen, $R S$-phenibut, and $R$-phenibut.

\section{Materials and Methods}

\subsection{General Procedure for the Asymmetric Michael Reaction}

Trans- $\beta$-nitrostyrene ( $27 \mathrm{mmol}, 1.0$ equiv.), the desired ester (54 mmol, 2.0 equiv.), and catalyst $1 \mathrm{~m}(1-0.0001 \mathrm{~mol} \%)$ were added to water $(50 \mathrm{~mL})$, and the reaction mixture was stirred at rt. The reaction was monitored by TLC. Upon completion of the reaction, ethyl acetate $(20 \mathrm{~mL})$ was added to the reaction mixture, and the obtained solution was washed twice with water $(2 \times 10 \mathrm{~mL})$, dried over anhydrous magnesium sulfate, filtered, 
and concentrated to yield the desired product. Each product was purified using column chromatography on a silica-gel column using hexane/methylene chloride (2:1) as the eluent.

\subsection{Reagents}

The fluorescent $\mathrm{Ca}^{2+}$ indicator Fluo-3 AM was purchased from Invitrogen (Leiden, the Netherlands). Cell Counting Kit-8 (CCK-8) solution was obtained from Dojindo Molecular Technologies.

\subsection{Cell Culture}

HEK293T was maintained in Dulbecco's modified Eagle's medium (DMEM; Invitrogen) supplemented with $10 \%$ fetal bovine serum (FBS) and $1 \%$ antibiotics at $37{ }^{\circ} \mathrm{C}$ in $100 \mathrm{~mm}$ cell culture dishes (Corning, NY, USA) under a humidified air atmosphere containing $5 \% \mathrm{CO}_{2}$.

\subsection{Cytotoxicity Analysis}

HEK293T cells $\left(1 \times 10^{4}\right.$ cells/well $)$ were seeded in a 96-well plate. The next day, cells were treated with compounds (10-fold, 6 point) and incubated for $24 \mathrm{~h}, 48 \mathrm{~h}$, and $72 \mathrm{~h}$. Subsequently, cell cytotoxicity was analyzed using the Cell Counting Kit-8 (CCK-8) solution (Dojindo Molecular Technologies, Inc, Rockville, MD, USA) following the manufacturer's procedure. The absorbance was detected at $450 \mathrm{~nm}$ via a microplate reader (Spectra MAX 340, Molecular Devices, Seoul, Korea). The data were analyzed through Prism software (GraphPad, San Diego, CA 92108, USA).

\subsection{Intracellular $\mathrm{Ca}^{2+}$ Measurements Using Confocal Laser Scanning Microscopy (CLSM)}

To detect intracellular $\mathrm{Ca}^{2+}$ level, HEK293T cells were seeded and incubated to 40-60\% confluence in a $35 \mathrm{~mm}$ diameter confocal dish $24 \mathrm{~h}$ prior to the experiment. The cells were loaded with $5 \mathrm{mM}$ fluorescent radiometric calcium indicator Fluo-3-acetoxymethyl (Fluo-3-AM; Invitrogen) for $30 \mathrm{~min}$ at $37^{\circ} \mathrm{C}$. The $\mathrm{Ca}^{2+}$ concentration was determined using CLSM (Zeiss LSM 700 Meta; Zeiss, Oberkochen, Germany). After washing with the medium, the culture plates were placed on a temperature-controlled microscope stage and observed at $200 \times$ microscope magnification. The excitation and emission wavelengths for signal detection were 488 and $515 \mathrm{~nm}$, respectively. The intensity analysis of intracellular calcium was performed using Zen software (Carl Zeiss).

\section{Conclusions}

Here, we report the development of catalysts based on $(R, R)$-1,2-diphenylethylenediamine for use as chiral bifunctional organocatalysts in asymmetric Michael additions to $\alpha, \beta$-unsaturated nitroalkenes under neutral conditions. These catalysts are economical due to their facile syntheses and the low catalyst loadings required for the reaction to take place (i.e., $\leq 0.0001 \mathrm{~mol} \%$ ). Importantly, the absence of metals and additives and the fact that the reaction could be carried out in air using water as a solvent renders our method environmentally friendly. In particular, we found that the Michael addition of malonate to $\alpha, \beta$-unsaturated compounds in the presence of catalyst $1 \mathrm{~m}$ and water gave high yields and excellent stereoselectivities due to the effect of fluorine since hydrogen bonding of the hydrophobic group of $1 \mathrm{~m}$ accelerated the catalytic reaction by stabilizing the transition state. We also demonstrated the further application of our method in the preparation of the bioactive compounds $R$ - or $S$-baclofen and phenibut through substitution of the nitroalkene aryl group with 4- $\mathrm{Cl}$ and $4-\mathrm{H}$ moieties. Moreover, in the presence of a lactam as the nitroalkene alkyl group, an advanced intermediate of phenylpiracetam was obtained in high yield and stereoselectivity. The study of this catalytic methodology can be applied to various pharmaceutical syntheses in the future. 
Supplementary Materials: The following are available online at https: / www.mdpi.com/article/ 10.3390/catal11091134/s1, Compound Characterization Data, Copy of NMR and MASS Spectra, Copy of HPLC Chromatograms, DFT Calculations for all Calculated Structures of the compounds mentioned in the text. Table S1. Catalyst screening. Table S2. Catalyst effects on the Michael reaction. Table S3. Substrate effects of malonate. Table S4. Catalyst effects on the Michael reaction.

Author Contributions: J.H.S. conceived and designed the project and wrote the manuscript. J.H.S. carried out the experiments and DFT calculations. J.H.S. organized the research. J.H.S., Y.H., J.H.K., H.S.K. and D.-C.H. analyzed the data, discussed the results, and commented on the manuscript. All authors have read and agreed to the published version of the manuscript.

Funding: This study was supported by the National Research Foundation of Korea (NRF- 2021M3A9G1097744), (NRF-2021R1A6A3A01087948). Also, this study was supported by a Korea University Grant.

Institutional Review Board Statement: The study was conducted according to the guidelines of the Declaration of Helsinki, and the animal experiments were approved by the Institutional Animal Care and Use Committee (IACUC) of Korea University (IACUC 2019-0028).

Acknowledgments: We are grateful for the financial support provided by K. H. Kim. We thank Byung Kook Ahn for providing assistance.

Conflicts of Interest: There are no conflicts of interest to declare.

\section{References}

1. MacMillan, D.W.C. The advent and development of organocatalysis. Nature 2008, 455, 304-308. [CrossRef]

2. Dalko, P.I.; Moisan, L. In the golden age of organocatalysis. Angew. Chem. Int. Ed. Engl. 2004, 43, 5138-5175. [CrossRef]

3. Grondal, C.; Jeanty, M.; Enders, D. Organocatalytic cascade reactions as a new tool in total synthesis. Nat. Chem. 2010, 2, 167-178. [CrossRef]

4. Curti, C.; Rassu, G.; Zambrano, V.; Pinna, L.; Pelosi, G.; Sartori, A.; Battistini, L.; Zanardi, F.; Casiraghi, G. Bifunctional cinchona alkaloid/thiourea catalyzes direct and enantioselective vinylogous Michael addition of 3-alkylidene oxindoles to nitroolefins. Angew. Chem. Int. Ed. Engl. 2012, 51, 6200-6204. [CrossRef]

5. Kwiatkowski, P.; Dudziński, K.; Łyżwa, D. Effect of high pressure on the organocatalytic asymmetric Michael reaction: Highly enantioselective synthesis of $\gamma$-nitroketones with quaternary stereogenic centers. Org. Lett. 2011, 13, 3624-3627. [CrossRef]

6. Zhang, Y.; Matsuo, Y.; Nakamura, E. Regiocontrolled synthesis of 1,2-di(organo)fullerenes via copper-assisted 1,4-aryl migration from silicon to carbon. Org. Lett. 2011, 13, 6058-6061. [CrossRef] [PubMed]

7. Narayan, S.; Muldoon, J.; Finn, M.G.; Fokin, V.V.; Kolb, H.C.; Sharpless, K.B. “On Water": Unique Reactivity of Organic Compounds in Aqueous Suspension. Angew. Chem. Int. Ed. 2005, 44, 3275-3279. [CrossRef] [PubMed]

8. Jung, Y.; Marcus, R.A. On the nature of organic catalysis "on water". J. Am. Chem. Soc. 2007, 129, 5492-5502. [CrossRef] [PubMed]

9. Dickerson, T.J.; Janda, K.D. Aqueous aldol catalysis by a nicotine metabolite: Dickerson and K. D. Janda. J. Am. Chem. Soc. 2002, 124, 3220-3221. [CrossRef]

10. Font, D.; Jimeno, C.; Pericàs, M.A. Polystyrene-supported hydroxyproline: An insoluble, recyclable organocatalyst for the asymmetric aldol reaction in water. Org. Lett. 2006, 8, 4653-4655. [CrossRef]

11. Wu, Y.; Zhang, Y.; Yu, M.; Zhao, G.; Wang, S. Highly efficient and reusable dendritic catalysts derived from N-prolylsulfonamide for the asymmetric direct aldol reaction in water. Org. Lett. 2006, 8, 4417-4420. [CrossRef]

12. Zu, L.; Wang, J.; Li, H.; Wang, W. A recyclable fluorous (S)-pyrrolidine sulfonamide promoted direct, highly enantioselective Michael addition of ketones and aldehydes to nitroolefins in water. Org. Lett. 2006, 8, 3077-3079. [CrossRef]

13. Vishnumaya, V.; Singh, V.K. Highly enantioselective water-compatible organocatalyst for Michael reaction of ketones to nitroolefins. Org. Lett. 2007, 9, 1117-1119. [CrossRef]

14. Yu, J.; Liu, Y.; Tang, J.; Wang, X.; Zhou, J. Highly Efficient “On Water" Catalyst-Free Nucleophilic Addition Reactions Using Difluoroenoxysilanes: Dramatic Fluorine Effects. Angew. Chem. Int. Ed. 2014, 53, 9512-9516. [CrossRef]

15. Giuffredi, G.T.; Gouverneur, V.; Bernet, B. Intramolecular OH $\cdots$ FC Hydrogen Bonding in Fluorinated Carbohydrates: CHF is a Better Hydrogen Bond Acceptor than $\mathrm{CF}_{2}{ }^{\dagger}$. Angew. Chem. Int. Ed. 2013, 52, 10524-10528. [CrossRef] [PubMed]

16. Dong, C.; Huang, F.; Deng, H.; Schaffrath, C.; Spencer, J.B.; O'Hagan, D.; Naismith, J.H. Crystal struture and mechanism of a bacterial fluorinating enzyme. Nature 2004, 427, 561-565. [CrossRef] [PubMed]

17. Dalvit, C.; Vulpetti, A. Fluorine-protein interactions and ${ }^{19} \mathrm{~F}$ NMR isotropic chemical shifts: An empirical correlation with implications for drug design. ChemMedChem 2011, 6, 104-114. [CrossRef] [PubMed]

18. Dalvit, C.; Vulpetti, A. Intermolecular and intramolecular hydrogen bonds involving fluorine atoms: Implications for recognition, selectivity, and chemical properties. ChemMedChem 2012, 7, 262-272. [CrossRef] [PubMed]

19. Sigman, M.S.; Jacobsen, E.N. Schiff Base Catalysts for the Asymmetric Strecker Reaction Identified and Optimized from Parallel Synthetic Libraries. J. Am. Chem. Soc. 1998, 120, 4901-4902. [CrossRef] 
20. Hiemstra, H.; Wynberg, H. Addition of aromatic thiols to conjugated cycloalkenones, catalyzed by chiral beta.-hydroxy amines. A mechanistic study of homogeneous catalytic asymmetric synthesis. J. Am. Chem. Soc. 1981, 103, 417-430. [CrossRef]

21. Dolling, U.H.; Davis, P.; Grabowski, E.J.J. Efficient catalytic asymmetric alkylations. 1. Enantioselective synthesis of (+)indacrinone via chiral phase-transfer catalysis. J. Am. Chem. Soc. 1984, 106, 446-447. [CrossRef]

22. McGilvra, J.D.; Unni, A.K.; Modi, K.; Rawal, V.H. Highly diastereo- and enantioselective Mukaiyama aldol reactions catalyzed by hydrogen bonding. Angew. Chem. Int. Ed. Engl. 2006, 45, 6130-6133. [CrossRef]

23. Huang, Y.; Unni, A.K.; Thadani, A.N.; Rawal, V.H. Hydrogen bonding: Single enantiomers from a chiral-alcohol catalyst. Nature 2003, 424, 146. [CrossRef]

24. Okino, T.; Hoashi, Y.; Takemoto, Y. Enantioselective Michael reaction of malonates to nitroolefins catalyzed by bifunctional organocatalysts. J. Am. Chem. Soc. 2003, 125, 12672-12673. [CrossRef]

25. Deb Majumdar, I.; Porco, J.A., Jr.; Devanabanda, A.; Fox, B.; Schwartzman, J.; Cong, H.; Porco, J.A., Jr.; Weber, H.C. Synthetic cyclohexenyl chalcone natural products possess cytotoxic activities against prostate cancer cells and inhibit cysteine cathepsins in vitro. Biochem. Biophys. Res. Commun. 2011, 416, 397-402. [CrossRef]

26. Cleland, W.W.; Kreevoy, M.M. Low-barrier hydrogen bonds and enzymic catalysis. Science 1994, 264, 1887-1890. [CrossRef] [PubMed]

27. Breslow, R. Determining the geometries of transition States by use of antihydrophobic additives in water. Acc. Chem. Res. 2004, 37, 471-478. [CrossRef] [PubMed]

28. Berne, B.J.; Weeks, J.D.; Zhou, R. Dewetting and hydrophobic interaction in physical and biological systems. Annu. Rev. Phys. Chem. 2009, 60, 85-103. [CrossRef] [PubMed]

29. Gruttadauria, M.; Giacalone, F.; Noto, R. Water in Stereoselective Organocatalytic Reactions. Adv. Synth. Catal. 2009, 351, 33-57. [CrossRef]

30. Mase, N.; Barbas, C.F., III. In water, on water, and by water: Mimicking nature's aldolases with organocatalysis and water. Org. Biomol. Chem. 2010, 8, 4043-4050. [CrossRef]

31. Shim, J.H.; Ha, D.C. Organocatalytic Asymmetric Michael Addition of Ketones to $\alpha, \beta$-Unsaturated Nitro Compounds. Catalysts 2020, 10, 618. [CrossRef]

32. Shim, J.H.; Ha, D.C. Enantioselective organocatalytic Michael reactions using chiral (R,R)-1,2-diphenylethylenedi-aminederived thioureas. RSC Adv. 2020, 10, 31808-31814. [CrossRef]

33. Reznikov, A.N.; Golovin, E.V.; Klimochkin, Y.N. Enantioselective synthesis of $\gamma$-aminobutyric acid derivatives by Ni(II)-catalyzed reaction of diethyl malonate with nitroalkenes. Russ. J. Org. Chem. 2013, 49, 663-668. [CrossRef]

34. Schreiner, P.R.; Wittkopp, A. H-Bonding Additives Act Like Lewis Acid Catalysts. Org. Lett. 2002, 4, 217-220. [CrossRef]

35. Paraskar, A.S.; Sudalai, A. Co-catalyzed reductive cyclization of azido and cyano substituted $\alpha, \beta$-unsaturated esters with NaBH4: Enantioselective synthesis of (R)-baclofen and (R)-rolipram. Tetrahedron 2006, 62, 4907-4916. [CrossRef]

36. Hajra, S.; Aziz, S.M.; Maji, R. Organocatalytic enantioselective conjugate addition of nitromethane to alkylidenemalonates: Asymmetric synthesis of pyrrolidine-3-carboxylic acid derivatives. RSC Adv. 2013, 3, 10185. [CrossRef]

37. Barnes, D.M.; Ji, J.; Fickes, M.G.; Fitzgerald, M.A.; King, S.A.; Morton, H.E.; Plagge, F.A.; Preskill, M.; Wagaw, S.H.; Wittenberger, S.J.; et al. Development of a catalytic enantioselective conjugate addition of 1,3-dicarbonyl compounds to nitroalkenes for the synthesis of endothelin-A antagonist ABT-546. Scope, mechanism, and further application to the synthesis of the antidepressant rolipram. J. Am. Chem. Soc. 2002, 124, 13097-13105. [CrossRef] [PubMed]

38. Okino, T.; Hoashi, Y.; Furukawa, T.; Xu, X.; Takemoto, Y. Enantio- and diastereoselective Michael reaction of 1,3-dicarbonyl compounds to nitroolefins catalyzed by a bifunctional thiourea. J. Am. Chem. Soc. 2005, 127, 119-125. [CrossRef]

39. Karolina, Z.; Karolina, K. Application of $\beta$-Phosphorylated Nitroethenes in [3+2] Cycloaddition Reactions Involving Benzonitrile N-Oxide in the Light of a DFT Computational Study. Organics 2021, 2, 3. [CrossRef]

40. Jasinski, R. $\beta$-Trifluoromethylated nitroethenes in Diels-Alder reaction with cyclopentadiene: A DFT computational study. J. Fluor. Chem. 2018, 206, 1-7. [CrossRef]

41. Manabe, K.; Kobayashi, S. Catalytic asymmetric carbon-carbon bond-forming reactions in aqueous media. Chemistry 2002, 8, 4094-4101. [CrossRef]

42. Bhowmick, S.; Bhowmick, K.C. Catalytic asymmetric carbon-carbon bond-forming reactions in aqueous media. Tetrahedron Asymmetry 2011, 22, 1945-1979. [CrossRef]

43. Bae, H.Y.; Song, C.E. Unprecedented Hydrophobic Amplification in Noncovalent Organocatalysis "on Water": Hydrophobic Chiral Squaramide Catalyzed Michael Addition of Malonates to Nitroalkenes. ACS Catal. 2015, 5, 3613-3619. [CrossRef]

44. Butler, R.N.; Coyne, A.G. Organic synthesis reactions on-water at the organic-liquid water interface. Org. Biomol. Chem. 2016, 14, 9945-9960. [CrossRef]

45. Wang, J.; Li, W.; Liu, Y.; Chu, Y.; Lin, L.; Liu, X.; Feng, X. Asymmetric Cyanation of Activated Olefins with Ethyl Cyanoformate Catalyzed by a Modular Titanium Catalyst. Org. Lett. 2010, 12, 1280-1283. [CrossRef]

46. Kimmel, K.L.; Weaver, J.D.; Lee, M.; Ellman, J.A. Catalytic enantioselective protonation of nitronates utilizing an organocatalyst chiral only at sulfur. J. Am. Chem. Soc. 2012, 134, 9058-9061. [CrossRef] [PubMed]

47. Zvejniece, L.; Svalbe, B.; Veinberg, G.; Grinberga, S.; Vorona, M.; Kalvinsh, I.; Dambrova, M. Investigation into stereoselective pharmacological activity of phenotropil. Basic Clin. Pharmacol. Toxicol. 2011, 109, 407-412. [CrossRef] [PubMed]

48. Gotoh, H.; Ishikawa, H.; Hayashi, Y. Diphenylprolinol silyl ether as catalyst of an asymmetric, catalytic, and direct Michael reaction of nitroalkanes with alpha, beta-unsaturated aldehydes. Org. Lett. 2007, 9, 5307-5309. [CrossRef] [PubMed] 
49. Zu, L.; Xie, H.; Li, H.; Wang, J.; Wang, W. Highly Enantioselective Organocatalytic Conjugate Addition of Nitromethane to $\alpha, \beta$-Unsaturated Aldehydes: Three-Step Synthesis of Optically Active Baclofen. Adv. Synth. Catal. 2007, 349, 2660-2664. [CrossRef]

50. Dambrova, M.; Zvejniece, L.; Liepinsh, E.; Cirule, H.; Zharkova, O.; Veinberg, G.; Kalvinsh, I. Comparative pharmacological activity of optical isomers of phenibut. Eur. J. Pharmacol. 2008, 583, 128-134. [CrossRef] [PubMed]

51. Jones, K.A.; Borowsky, B.; Tamm, J.A.; Craig, D.A.; Durkin, M.M.; Dai, M.; Yao, W.J.; Johnson, M.; Gunwaldsen, C.; Huang, L.Y.; et al. GABA(B) receptors function as a heteromeric assembly of the subunits GABA(B)R1 and GABA(B)R2. Nature 1998, 396, 674-679. [CrossRef] [PubMed]

52. Kita, M.; Goodkin, D.E. Drugs used to treat spasticity. Drugs 2000, 59, 487-495. [CrossRef] [PubMed]

53. Sun, B.; Chen, L.; Liu, L.; Xia, Z.; Pin, J.P.; Nan, F.; Liu, J. A negative allosteric modulator modulates GABAB-receptor signalling through GB2 subunits. Biochem. J. 2016, 473, 779-787. [CrossRef]

54. Addolorato, G.; Leggio, L.; Ferrulli, A.; Cardone, S.; Vonghia, L.; Mirijello, A.; Abenavoli, L.; D'Angelo, C.; Caputo, F.; Zambon, A.; et al. Effectiveness and safety of baclofen for maintenance of alcohol abstinence in alcohol-dependent patients with liver cirrhosis: Randomised, double-blind controlled study. Lancet 2007, 370, 1915-1922. [CrossRef]

55. Rolland, B.; Bordet, R.; Cottencin, O. Alcohol-dependence: The current French craze for baclofen. Addiction 2012, 107, 848-849. [CrossRef] [PubMed]

56. Geoffroy, P.A.; Auffret, M.; Deheul, S.; Bordet, R.; Cottencin, O.; Rolland, B. Baclofen-induced manic symptoms: Case report and systematic review. Psychosomatics 2014, 55, 326-332. [CrossRef] [PubMed] 